\title{
Analytical Modeling of Flux-Switching In-Wheel Motor Using Variable Magnetic Equivalent Circuits
}

\author{
Y. Tang, J. J. H. Paulides, and E. A. Lomonova \\ Electromechanics and Power Electronics Group, Department of Electrical Engineering, Eindhoven University of Technology, \\ Den Dolech 2, 5612 AZ Eindhoven, The Netherlands \\ Correspondence should be addressed to Y. Tang; y.tang1@tue.nl
}

Received 28 June 2013; Accepted 6 August 2013; Published 1 January 2014

Academic Editors: R. Kazemi, O. Prentkovskis, and D. Sanders

Copyright (C) 2014 Y. Tang et al. This is an open access article distributed under the Creative Commons Attribution License, which permits unrestricted use, distribution, and reproduction in any medium, provided the original work is properly cited.

Flux-switching motors (FSM) are competitive candidates for in-wheel traction systems. However, the analysis of FSMs presents difficulty due to their complex structure and heavy magnetic saturation. This paper presents a methodology to rapidly construct, adapt, and solve a variable magnetic equivalent circuit of 12-stator-slot 10-rotor-tooth (12/10) FSMs. Following this methodology, a global MEC model is constructed and used to investigate correlations between the radial dimensions and the open-circuit phase flux linkage of the 12/10 FSM. The constructed MEC model is validated with finite element analysis and thus proved to be able to assist designers with the preliminary design of flux-switching motors for different in-wheel traction systems.

\section{Introduction}

With the rising concern on environmental issues, hybrid/electric vehicles (HEV/EV) have attracted an increasing interest from public and industry since the end of the 20th century. The fast developing technology of HEV/EV has also introduced a revolutionary traction concept to vehicles designers, namely, in-wheel traction. By putting electric motors in the wheels, the drivetrain is greatly simplified. Mechanical axes can thus be removed, which creates extra space for the cargo and reduces the total weight of the vehicle $[1,2]$, as shown in Figure 1(a). These advantages of simplicity and freedom make the in-wheel traction a preferable traction mode for vehicle designers.

For the design of an in-wheel traction system, there are two possible topologies, namely, direct driving and indirect driving. In a direct-driving system, the electrical motor is directly driving the wheel without a gearbox, as shown in Figure 1(b). This direct-driving in-wheel module provides a maximum simplicity for the system design; thus, it is commonly adopted in most existing in-wheel traction systems.

However, due to the absence of gearbox, the electrical motor of a direct-driving system needs to provide a high torque. The high torque in-wheel motor increases the wheel mass and consequently reduces the passenger comfort [3].
To solve this problem, an indirect-driving in-wheel module, shown in Figure 2(a), can be adopted, in which the electrical motor is indirectly driving the wheel through a gearbox. By this means, the required torque for the motor is reduced (Figure 2(b)), and the wheel mass is maintained. Different topologies of the in-wheel traction lead to different requirements and constraints for the motor design. Nevertheless, in both topologies, electrical motors need to have a high torque density with certain level of ruggedness.

Permanent magnet synchronous motor (PMSM) is advantageous in torque production. However, the performance of PMSM is usually limited due to crucial limits on the thermal and mechanical conditions of the permanent magnets in the rotor. Compared to PMSM, switched reluctance motor (SRM), on the one hand, presents better ruggedness benefitting from the robust rotor structure and, on the other hand, lower torque density resulting from the absence of a second magnetic excitation source $[1,2,4]$.

Flux-switching motors (FSM), including flux-switching permanent magnet motor (FSPMM) and dc-excited fluxswitching motor (DCE-FSM) as shown in Figure 3, are preferably considered as they combine the advantages of both SRM and PMSM. By placing the permanent magnets in the stator, FSPMMs gain a similar robust rotor structure as SRMs while preserving comparable torque density as PMSMs due to the 


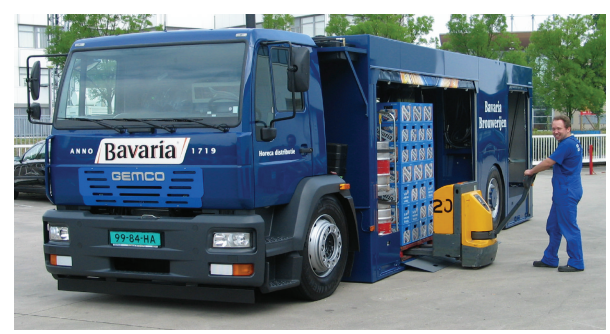

(a)

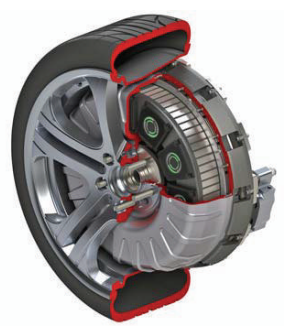

(b)

FIGURE 1: In-wheel traction-(a) an electric truck with large cargo and (b) an in-wheel motor.

flux-concentrating effect [5-7]. Hence, they are a competitive candidate for the application of in-wheel traction where high torque and ruggedness are both concerned.

However, the analysis of FSMs presents great difficulty due to their complex structure and heavy magnetic saturation. Numerical methods, such as finite element analysis (FEA), usually require a significant computational time despite of relatively high accuracy. Thus, they are not preferred for preliminary motor design, for example, initial sizing $[8,9]$. In contrast, certain analytical methods, such as Fourier analysis, are relatively faster in computing. However, they are less accurate in solving nonlinear magnetic problems resulting from magnetic saturation [10-13]. Magnetic equivalent circuits (MEC) provide a good compromise between computational time and accuracy. Hence, they have been extensively used for analyzing subsystems of electrical motors and actuators which are prone to saturation, for example, the stator and rotor teeth or back iron [14-21].

In this paper, 12-stator-slot 10-rotor-tooth (12/10) FSMs selected for various in-wheel traction systems are modeled using nonlinear variable MEC. The methods for constructing and solving the variable MEC of the 12/10 FSM are introduced in Sections 2 and 3. Using the constructed variable MEC, correlations between certain design parameters and the opencircuit phase flux linkage of 12/10 FSM are investigated. The results obtained using the MEC method are validated by the FEA results in Section 4.

\section{Variable Magnetic Equivalent Circuits}

The airgap magnetic flux distribution of an FSM is highly sensitive to its rotor position due to the double-salient structure of this motor. Hence, the global MEC of the motor needs to be frequently updated in synchronism with rotor position. At certain positions, not only the permeance values but also the

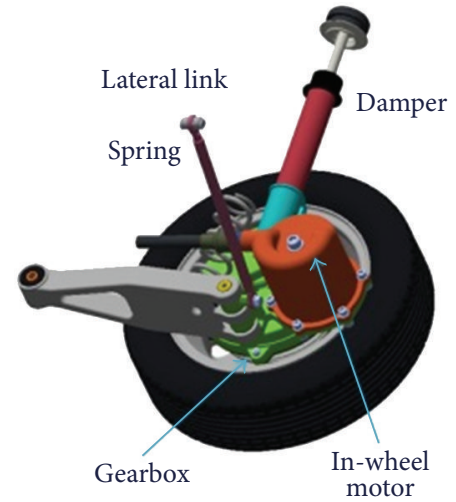

(a)

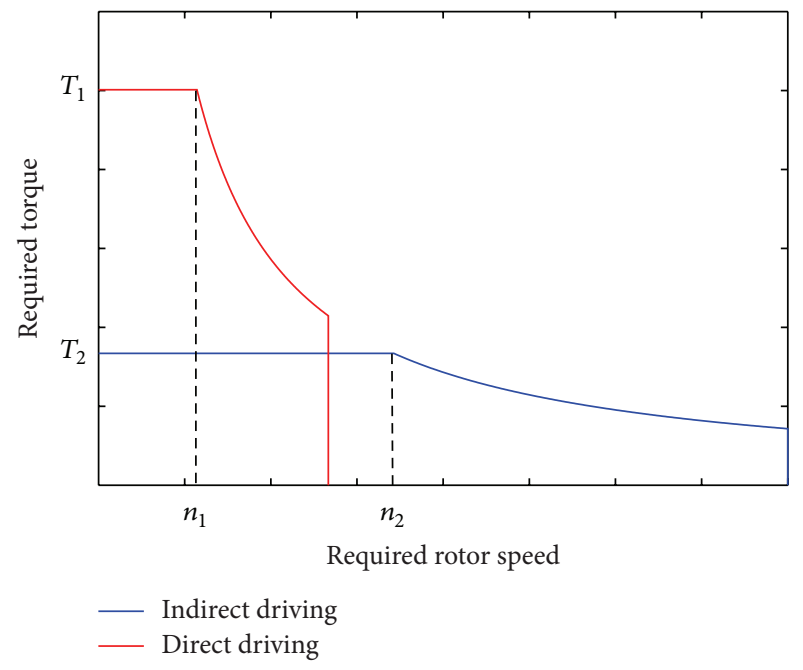

(b)

FIGURE 2: Light-weight in-wheel module-(a) the module structure and (b) torque-speed requirements for electrical motors in directdriving and indirect-driving in-wheel modules.

circuit topology should be changed. This repetitive adaption usually requires a considerable amount of manual effort and makes it especially difficult to implement the MEC method for motors with low periodicity, in which an elaborate global MEC is required.

In this paper, the global MEC of $12 / 10 \mathrm{FSM}$ is constructed based on a number of MEC modules, including stator MEC modules, rotor MEC modules, and airgap MEC modules. By this means, the requirement of adapting the global MEC is addressed to specific MEC modules. Hence, the involved workload is reduced.

2.1. Categorization of MEC Elements. The MEC method is based on the analogies of the quantity relations in a magnetic field and in a resistive electric circuit $[22,23]$, as

$$
\Phi=\frac{\mathscr{F}}{\mathscr{R}}=\mathscr{F} \cdot \mathscr{P},
$$

in which $\Phi$ is the flux, $\mathscr{F}$ is the magnetomotive force (mmf), $\mathscr{R}$ is the reluctance, and $\mathscr{P}$ is the permeance. 


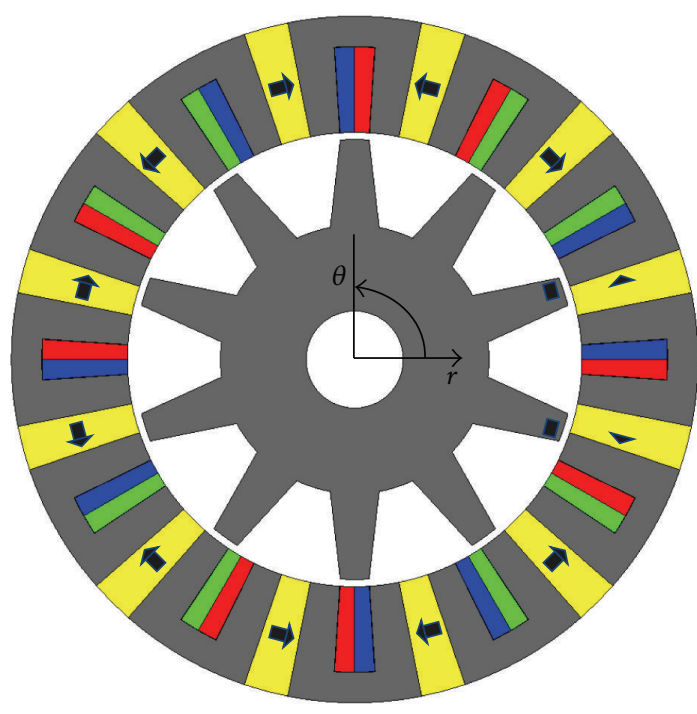

Three-phase armature windings

Permanent magnets

(a) $12 / 10$ FSPMM

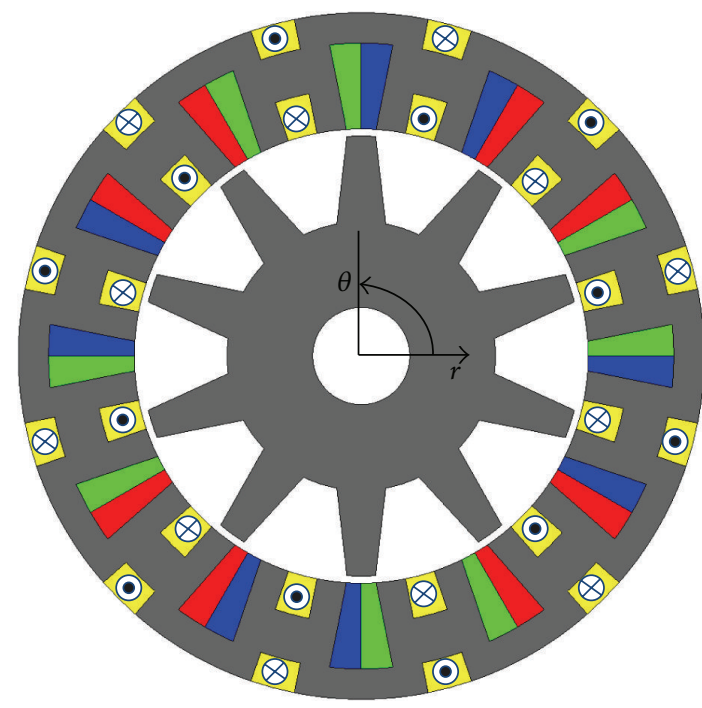

Ferromagnetic material

$\otimes$ Dc field windings

(b) $12 / 10$ DCE-FSM

FIGURE 3: Cross-sections of (a) flux-switching permanent magnet motor (FSPMM) and (b) dc-excited flux-switching motor (DCE-FSM).

In a MEC, permanent magnets are modeled as $\mathrm{mmf}$ sources with reluctances in series or as flux sources with reluctances in parallel, shown in Figure 4 . In these models, the values of mmf source $\mathscr{F}_{\text {PM }}$ and flux source $\Phi_{\text {PM }}$ can be calculated as

$$
\begin{aligned}
\mathscr{F}_{\mathrm{PM}} & =\frac{B_{r}}{\mu_{0} \mu_{r}} l_{\mathrm{PM},}, \\
\Phi_{\mathrm{PM}} & =B_{r} A_{\mathrm{PM},}
\end{aligned}
$$

in which $B_{r}, \mu_{r}, l_{\mathrm{PM}}$, and $A_{\mathrm{PM}}$ are the remanent magnetic flux density, the relative permeability, the length in the magnetization direction, and the area of the cross-section perpendicular to the magnetization direction, respectively, of the permanent magnet.

Reluctances or their reciprocals permeances are approximately calculated by merging an area of flux paths into flux tubes. These flux tubes are defined as objects that enclose the flux lines with their side face parallel and head face perpendicular to them [22].

For the 12/10 FSM, seven types of flux tubes are identified, shown in Figure 5. The equally distributed lines in each cross-section indicate the flux paths, and the magnetic properties along the longitudinal dimension of each flux tube are assumed to be homogeneous.

To simplify the permeance calculation of flux tubes, two coordinate systems are used, namely, Cylindrical and Cartesian. The two types of flux tubes, shown in Figures 5(a) and 5(b), are defined in the Cylindrical coordinate system. The other four flux tubes, shown in Figures 5(c)-5(f), are defined in the Cartesian coordinate system.

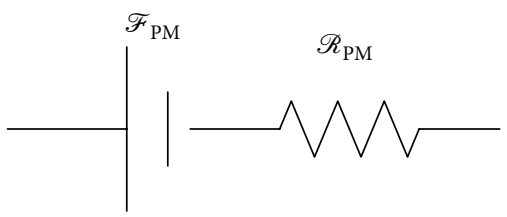

(a)

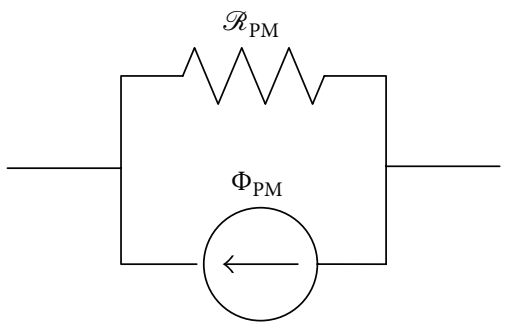

(b)

FIGURE 4: Magnetic equivalent circuit models of permanent magnets as (a) an mmf source and a reluctance in series; (b) a flux source and a reluctance in parallel.

2.2. Stator MEC Modules. A stator MEC module is defined as the MEC model that represents the magnetic flux distribution in a unit section of the stator, that is, the section between central axes of each two neighboring stator slots, as shown in Figure 6(a).

The resulting MEC module is shown in Figure 6(b), where the nodes and branches are numbered in Arabic and Roman numerals, respectively. 


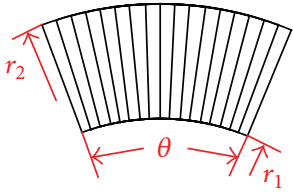

(a)

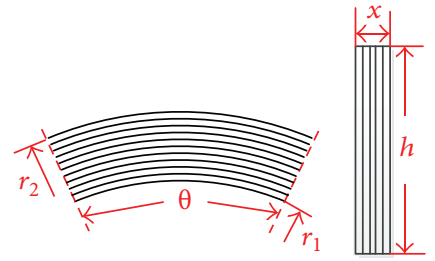

(b)

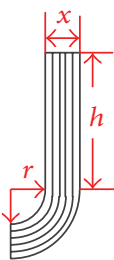

(d)

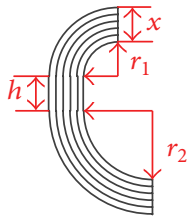

(e)

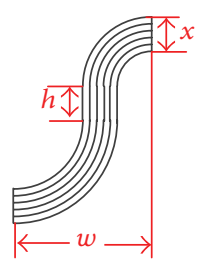

(f)

FiguRE 5: Transversal cross-sections of flux tubes and their permeances: (a) $\mathscr{P}=\mu L \theta / \ln \left(r_{2} / r_{1}\right) ;$ (b) $\mathscr{P}=\mu L \ln \left(r_{2} / r_{1}\right) / \theta$; (c) $\mathscr{P}=\mu L x / h$; (d) $\mathscr{P}=2 \mu L \cdot \ln [1+\pi x /(\pi r+2 h)] / \pi ;(\mathrm{e}) \mathscr{P}=\mu L \cdot \ln \left[1+2 \pi x /\left(\pi r_{1}+\pi r_{2}+2 h\right)\right] / \pi ;(\mathrm{f}) \mathscr{P}=2 \mu L x /(\pi w+2 h)$.

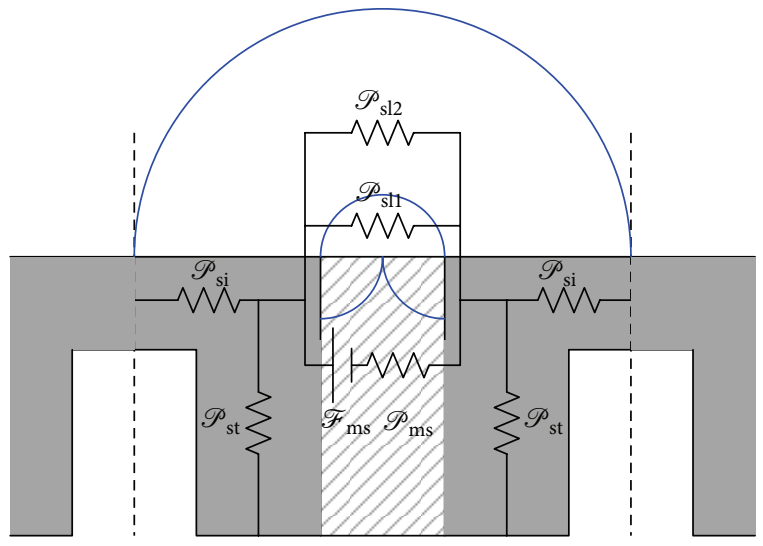

(a)

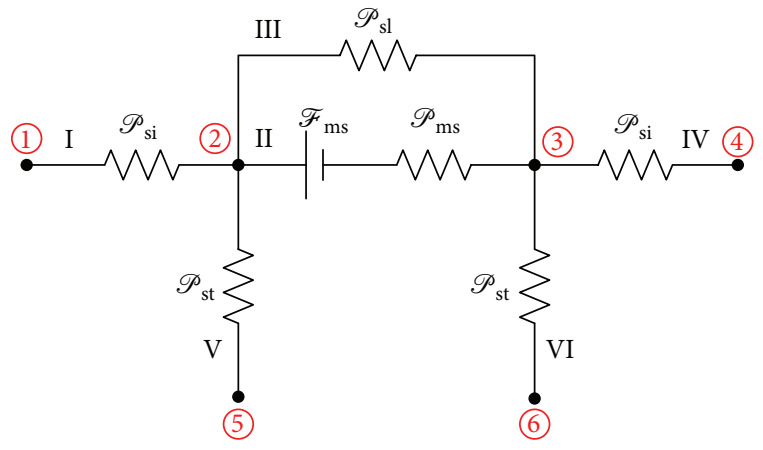

(b)

FIGURE 6: Stator MEC module of FSM: (a) a stator section; (b) magnetic equivalent circuit for a stator section $\left(\mathscr{P}_{\mathrm{sl}}=\mathscr{P}_{\mathrm{sl} 1}+\mathscr{P}_{\mathrm{sl} 2}\right)$.

The magnetic source in the stator section is modeled as an mmf source $\mathscr{F}_{\text {ms }}$ with a permeance $\mathscr{P}_{\text {ms }}$ in series, as shown in Figure 6(a), in which $\mathscr{F}_{\text {ms }}$ is calculated using (2), and $\mathscr{P}_{\mathrm{ms}}$ represents the permeance of the permanent magnet or the iron core, accordingly. The flux paths in the stator tooth and stator back iron are modeled as different flux tubes with permeances $\mathscr{P}_{\text {st }}$ and $\mathscr{P}_{\text {si }}$, respectively. The leakage flux outside the stator is also included and modeled as two parallel flux tubes with permeances $\mathscr{P}_{\text {sl1 }}$ and $\mathscr{P}_{\text {sl2 }}$, respectively, as can be seen in Figure 6(a). The types of flux tubes selected from Figure 5 for the permeance calculation are summarized in Table 1 .
TABLE 1: Types of flux tubes in the stator and rotor MEC modules.

\begin{tabular}{lcccccc}
\hline $\mathscr{P}_{\mathrm{ms}}$ & $\mathscr{P}_{\mathrm{st}}$ & $\mathscr{P}_{\mathrm{si}}$ & $\mathscr{P}_{\text {sl1 }}$ & $\mathscr{P}_{\mathrm{s} 2}$ & $\mathscr{P}_{\mathrm{rt}}$ & $\mathscr{P}_{\mathrm{ri}}$ \\
\hline $\mathrm{b}$ & $\mathrm{a}$ & $\mathrm{b}$ & $\mathrm{f}$ & $\mathrm{e}$ & $\mathrm{b}$ & $\mathrm{a}$ \\
\hline
\end{tabular}

For the 12/10 FSM, the MEC of the stator consists of twelve stator MEC modules that are similar to Figure 6(b). However, when connecting the circuits, the polarity of the mmf source on branch II should be reversed in each neighboring module. Furthermore, it is worth noting that the actual magnetic flux paths in the stator vary with rotor position. However, to simplify the modeling problem, this variation is neglected as the permeability of the ferromagnetic material is relatively large under nonsaturated conditions.

2.3. Rotor MEC Modules. A rotor MEC module is defined as the MEC model that represents the magnetic flux distribution in a unit section of rotor. This rotor section is obtained by dividing the rotor of the FSM into equal sections, each with a rotor tooth in the middle, as shown in Figure 7(a).

The resulting MEC module is shown in Figure 7(b), where the nodes and branches are numbered in Arabic and Roman numerals, respectively. In this module, the flux paths in the rotor tooth and rotor back iron are modeled as different flux tubes with permeances $\mathscr{P}_{\text {rt }}$ and $\mathscr{P}_{\text {ri }}$, respectively. The types of flux tubes selected from Figure 5 for the permeance calculation are summarized in Table 1.

For the 12/10 FSM, the MEC of the rotor consists of ten rotor MEC modules. With the same simplifications as applied to the stator MEC modules, the rotor MEC modules are also assumed to be invariant to rotor position.

2.4. Airgap MEC Modules. An airgap MEC module is defined as the MEC model for the magnetic flux distribution in the airgap area around a rotor tooth. The airgap magnetic field is modeled with a certain number of different airgap MEC modules for different rotor positions.

To limit the number of module varieties, this paper divides a stator section into eight intervals, shown in Figure 8. A different airgap MEC module is used only when the rotor tooth enters a different interval.

It can be seen from Figure 8 that, with respect to the central axis of the stator section, the four intervals on the left, numbered from 1 to 4 , are symmetric to the four on the right, 


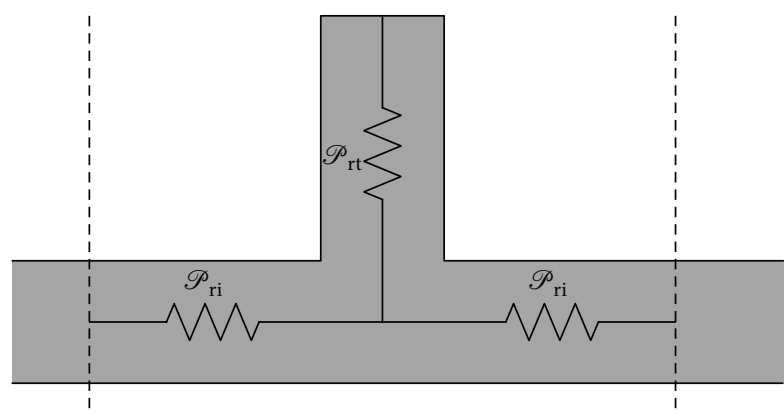

(a)

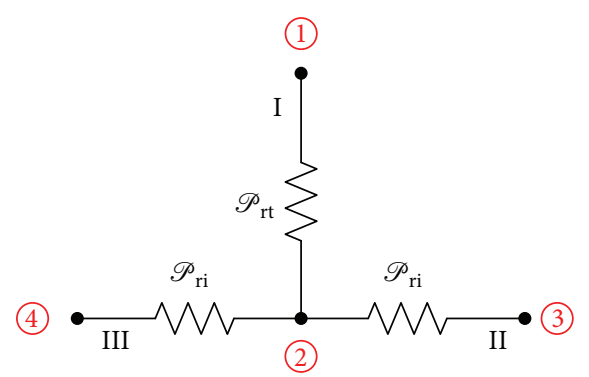

(b)

FIGURE 7: Rotor MEC module of FSM: (a) a rotor section; (b) magnetic equivalent circuit for a rotor section.

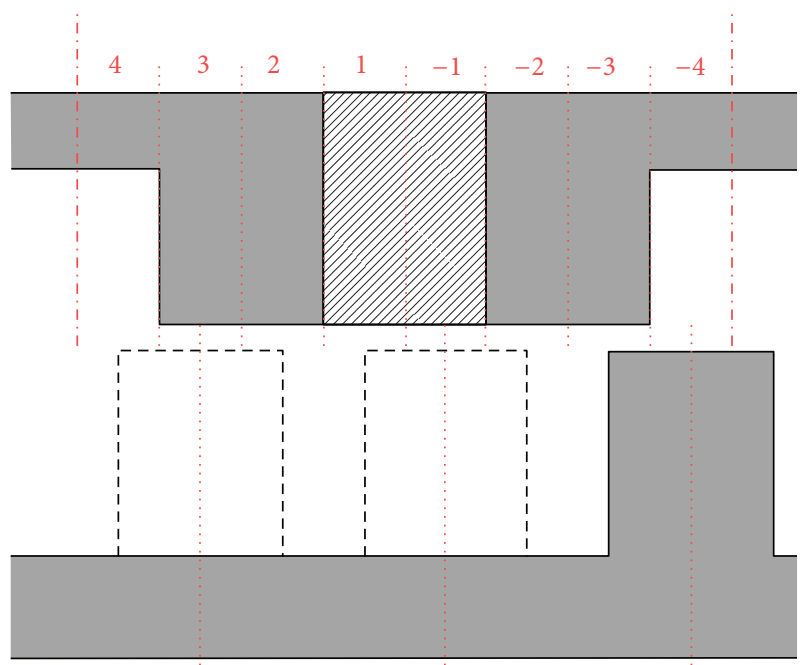

FIGURE 8: Interval divisions of a stator section for positioning a rotor tooth.

numbered from -1 to -4 ; thus, only four different airgap MEC modules are needed.

FEA is performed on the model of 12/10 FSMs to obtain an impression of the magnetic flux distribution in the airgap during the rotor's rotation, shown in Figure 9.

Based on the FEA results, the airgap flux distribution is simplified by grouping the flux paths into a certain number of flux tubes, as shown in Figures 10(a), 11(a), 12(a), and 13(a), in which $\theta_{x}$ is the angle that the rotor tooth has traveled in the corresponding interval. The types of flux tubes selected
TABLE 2: Types of flux tubes in different airgap MEC modules.

\begin{tabular}{llllllllllll}
\hline $\mathscr{P}_{i, j}$ & & & & \multicolumn{1}{c}{$j$} & & & & & \\
& 1 & 2 & 3 & 4 & 5 & 6 & 7 & 8 & 9 & 10 & 11 \\
\hline $\mathscr{P}_{1, j}$ & d & e & d & c & d & d & f & d & c & d & - \\
$\mathscr{P}_{2, j}$ & d & f & e & d & c & d & f & f & d & c & d \\
$\mathscr{P}_{3, j}$ & d & f & e & d & c & e & f & d & - & - & - \\
$\mathscr{P}_{4, j}$ & d & f & d & d & c & d & e & f & - & - & - \\
\hline
\end{tabular}

TABLE 3: Variation of the rotor position state during rotation.

\begin{tabular}{|c|c|c|c|c|c|c|c|c|c|c|}
\hline & $\mathrm{T} 1$ & $\mathrm{~T} 2$ & T3 & $\mathrm{T} 4$ & T5 & T6 & T7 & T8 & T9 & T10 \\
\hline P1 & -4 & -3 & -1 & 1 & 3 & -4 & -3 & -1 & 1 & 3 \\
\hline P2 & -4 & -3 & -1 & 2 & 3 & -4 & -3 & -1 & 2 & 3 \\
\hline P3 & -4 & -2 & -1 & 2 & 3 & -4 & -2 & -1 & 2 & 3 \\
\hline P4 & -4 & -2 & -1 & 2 & 4 & -4 & -2 & -1 & 2 & 4 \\
\hline P5 & -4 & -2 & 1 & 2 & 4 & -4 & -2 & 1 & 2 & 4 \\
\hline P6 & -3 & -2 & 1 & 2 & 4 & -3 & -2 & 1 & 2 & 4 \\
\hline P7 & -3 & -2 & 1 & 3 & 4 & -3 & -2 & 1 & 3 & 4 \\
\hline P8 & -3 & -1 & 1 & 3 & 4 & -3 & -1 & 1 & 3 & 4 \\
\hline & -3 & -1 & 1 & 3 & -4 & -3 & -1 & 1 & 3 & -4 \\
\hline & -3 & -1 & 2 & 3 & -4 & -3 & -1 & 2 & 3 & -4 \\
\hline & -2 & -1 & 2 & 3 & -4 & -2 & -1 & 2 & 3 & -4 \\
\hline & $\ldots$ & $\ldots$ & $\ldots$ & $\ldots$ & $\ldots$ & $\ldots$ & $\ldots$ & $\ldots$ & $\ldots$ & \\
\hline
\end{tabular}

from Figure 5 for the permeance calculation are summarized in Table 2.

Hence, four different airgap MEC modules are built with variable permeances, as shown in Figures 10(b), 11(b), 12(b), and $13(\mathrm{~b})$. In these models, permeances are expressed as functions of the angle $\theta_{x}$ using the equations introduced in Figure 5. By integrating the parallel permeances, topologies of the four modules are obtained, as shown in Figures 10(c), $11(\mathrm{c}), 12(\mathrm{c})$, and 13(c).

For the 12/10 FSM, the MEC of airgap consists of ten airgap MEC modules selected corresponding to the traveling interval of each rotor tooth.

\section{Construction and Solving Method}

3.1. Position State Shifting. Periodicity of the $12 / 10$ FSM allows modeling only half of the motor. Hence, the global MEC of this motor with certain rotor position is assembled using six stator MEC modules (S1-S6), five rotor MEC modules (T1-T5), and five airgap MEC modules (A1-A5), shown in Figure 14.

Each airgap MEC module varies with rotor position. Therefore, this paper proposes a strategy named "position state shifting". In this strategy, a shifting scheme of rotor position states is allocated to indicate the sequence of the airgap MEC module types for each position. These rotor position states are arrays of interval numbers of the rotor teeth. With certain slot/tooth configurations, for example, $12 / 10$, the shift of rotor position states in an electrical period can be mathematically predicted.

Table 3 presents the shifting scheme of position states for the considered 12/10 FSM, in which the columns T1-T10 refer 


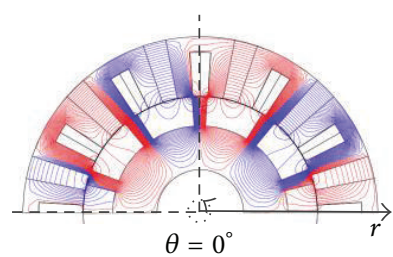

(a)

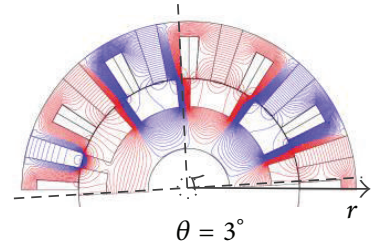

(b)
FIGURE 9: FEA results of equipotential contour in part of 12/10 FSM while a rotor tooth travels in (a) interval 1 and (b) interval 2.

to the ten rotor teeth, the rows P1-P8 refer to the position states, and the numbers show the traveling intervals of each rotor tooth. It can be seen that the first eight states (P1-P8) are repeated for different starting-points. This repetition suggests a possibility in reducing the number of varieties of the global MEC.

3.2. Incidence Matrix. The MEC modules can be mathematically described using the incidence matrix method [24], explained as follows.

For a circuit with $m$ nodes and $n$ branches, its incidence matrix $\mathbf{A}$ is an $m \times n$ matrix in which

$$
\mathbf{A}_{i j}= \begin{cases}1, & \text { if branch } j \text { begins from node } i, \\ -1, & \text { if branch } j \text { ends to node } i \\ 0, & \text { if branch } j \text { is not connected to node } i\end{cases}
$$

Variables of this circuit can be further defined in the form of matrix or vector listed as follows:
A: incidence matrix ( $m \times n$ matrix);
$V$ : magnetic potential on each node ( $m \times 1$ vector);
$U:$ mmf drop across each branch $(n \times 1$ vector);
$\varphi$ : flux through each branch $(n \times 1$ vector);
$E:$ mmf source in each branch $(n \times 1$ vector $)$;

$\Lambda$ : permeance of each branch $(n \times n$ diagonal matrix);

R: reluctance of each branch $(n \times n$ diagonal matrix).

According to Kirchhoff Circuit Laws, following equations can be derived:

$$
\begin{gathered}
U=\mathbf{A}^{t} \cdot V, \\
\mathbf{A} \cdot \phi=0 \\
U=\mathbf{R} \cdot \phi+E=\Lambda^{-1} \cdot \phi+E .
\end{gathered}
$$

Therefore, with given $\mathbf{A}, \boldsymbol{\Lambda}$, and $E$, the magnetic potentials can be solved as

$$
V=\left(\mathbf{A} \cdot \mathbf{\Lambda} \cdot \mathbf{A}^{t}\right)^{-1} \cdot(\mathbf{A} \cdot \mathbf{\Lambda} \cdot E) .
$$

Hence, using the incidence matrix method, the global MEC is assembled and solved. The magnetic potentials of

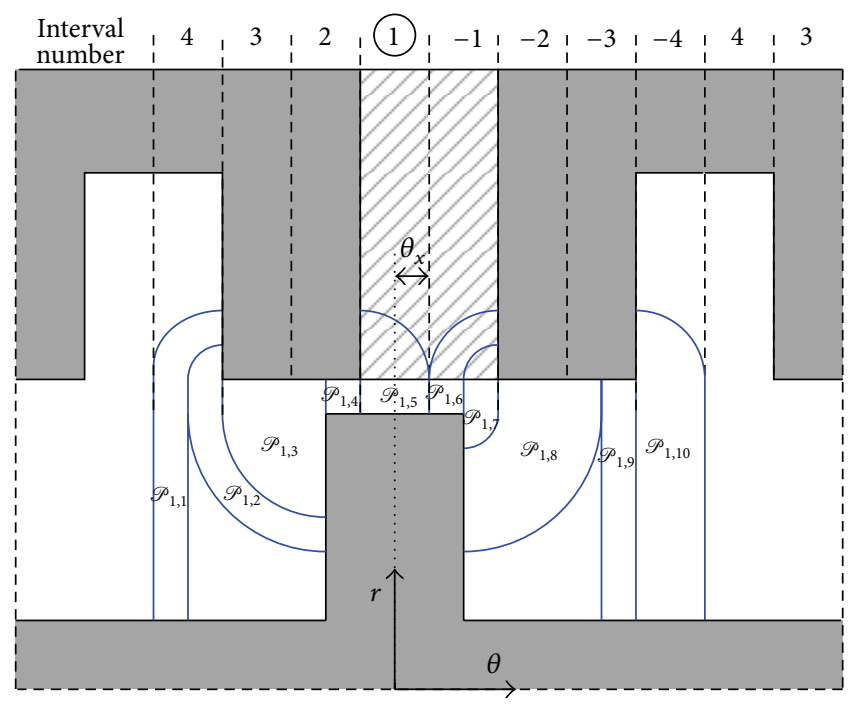

(a)

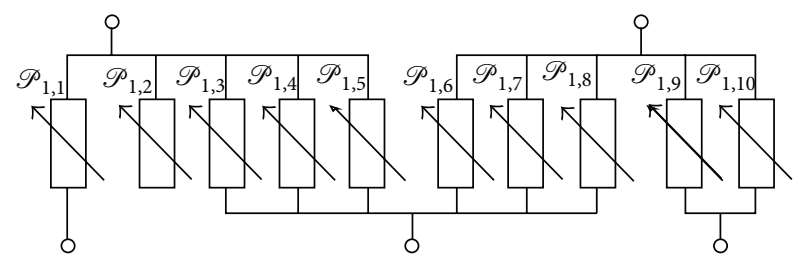

(b)

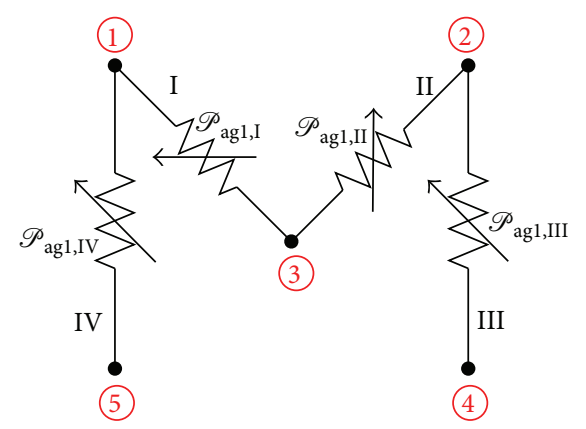

(c)

FIgURE 10: Airgap MEC module 1: (a) flux tubes in the airgap while a rotor tooth travels in interval 1; (b) detailed magnetic equivalent circuit; (c) topology of airgap MEC module 1.

each node are computed; therefore, the magnetic flux through each flux tube is obtained.

In addition, magnetic saturation is taken into account by iteratively solving the global MEC to identify the applicable relative permeability used for certain flux tube.

\section{Validation with Finite Element Analysis}

The nonlinear MEC model of 12/10 FSMs is constructed and used to investigate the correlation between the open-circuit phase flux linkage resulting and certain design parameters such as the motor size and the airgap length. To validate the accuracy of this model, the results of open-circuit phase flux linkage are compared to corresponding FEA results. To 


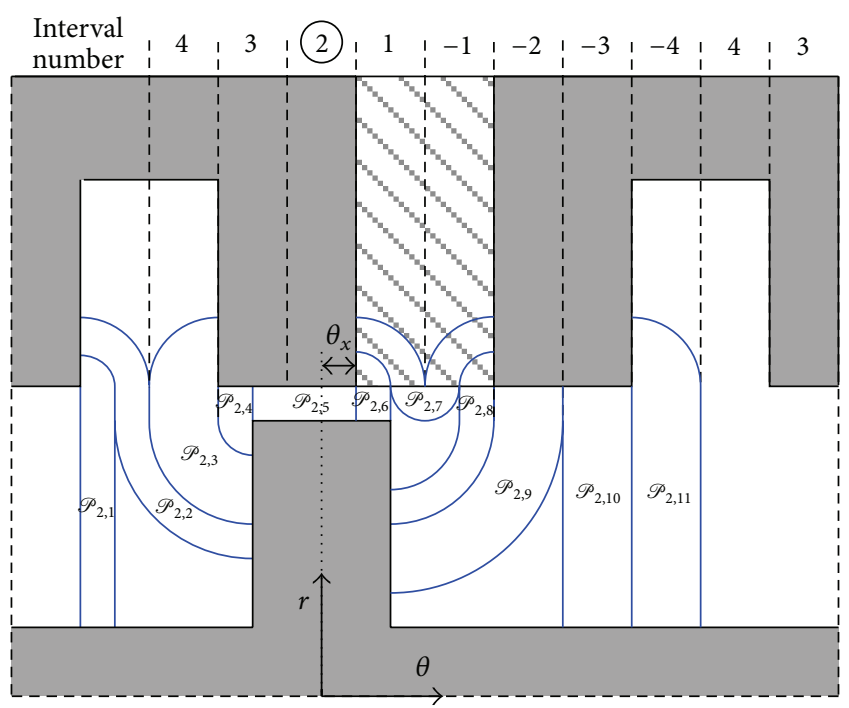

(a)

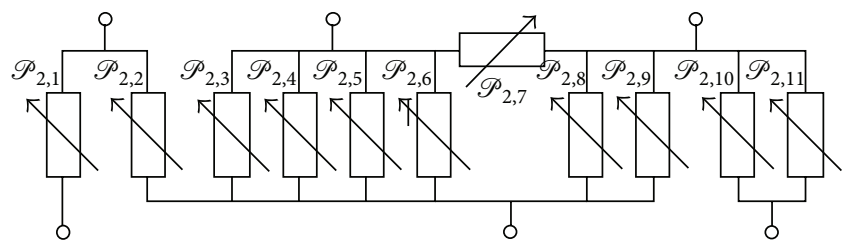

(b)

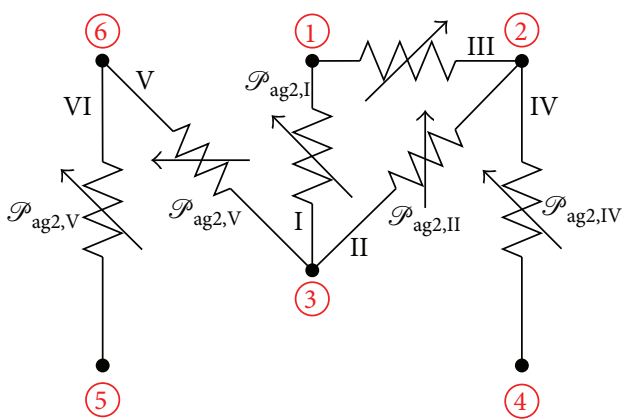

(c)

FIGURE 11: Airgap MEC module 2: (a) flux tubes in the airgap while a rotor tooth travels in interval 2; (b) detailed magnetic equivalent circuit; (c) topology of airgap MEC module 2.

simplify the comparison, the number of turns is assumed to be $n_{c}=1$. Properties of steel laminations and permanent magnets adopted for the modeling are shown in Table 4.

4.1. Motor Size. To research the robustness of the method, three sets of geometric parameters, noted as Geom1, Geom2, and Geom 3 in Figure 15 and Table 5, are implemented into the MEC and FEA models of 12/10 FSPMM. In Figure 16, the MEC results show a good agreement with the FEA results.

4.2. Airgap Length. The airgap length of an electrical motor is an important parameter for the motor design as it directly influences the airgap flux density and the saturation level in the rotor and stator iron. Therefore, the flexibility of the

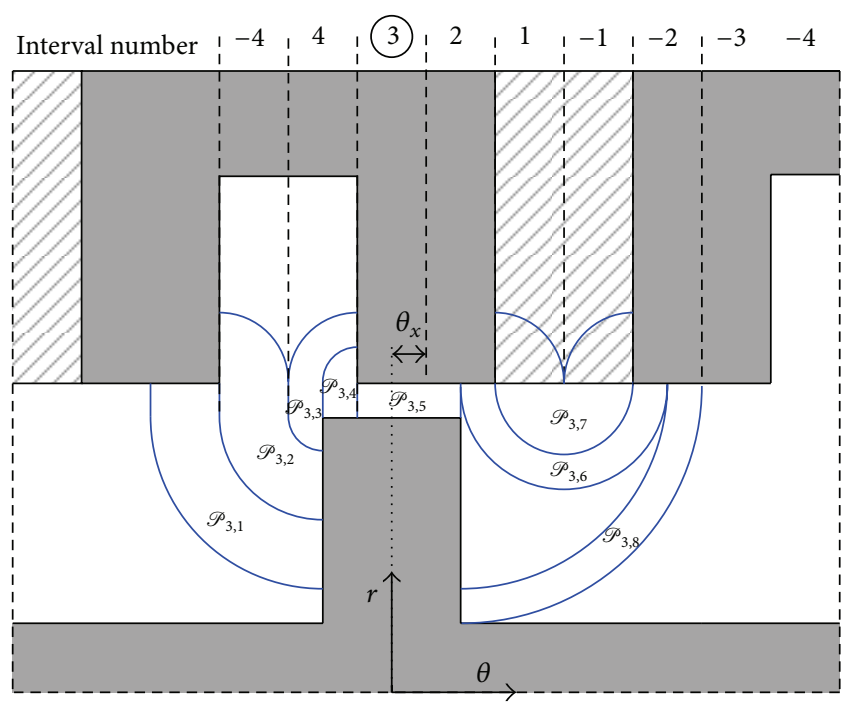

(a)

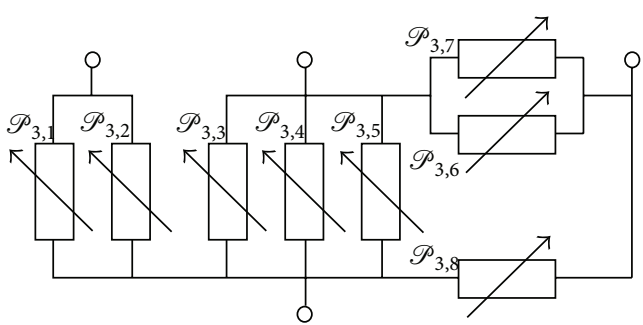

(b)

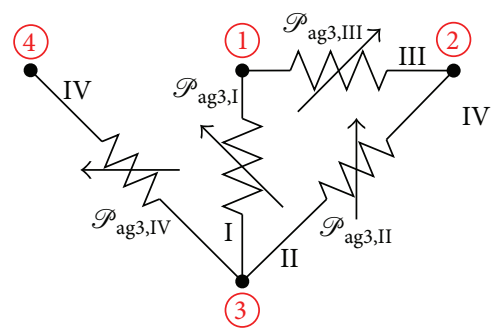

(c)

FIGURE 12: Airgap MEC module 3: (a) flux tubes in the airgap while a rotor tooth travels in interval 3; (b) detailed magnetic equivalent circuit; (c) topology of airgap MEC module 3.

MEC model for different airgap lengths is researched. In this respect, Figure 17 illustrates the open-circuit phase fluxlinkage results of the 12/10 FSPMM (Geoml) with different values of the airgap length $\delta$. It can be seen that the MEC results are close to the FEA results, although the later presents an improved sensitivity to the airgap length variation. This difference suggests room for improving the accuracy of the MEC model, which can be achieved by refining the MEC modules while preserving the structure of the global MEC model.

\section{Conclusions}

Flux-switching motors (FSM) combine the advantages of synchronous motors and switched reluctance motors; thus, 


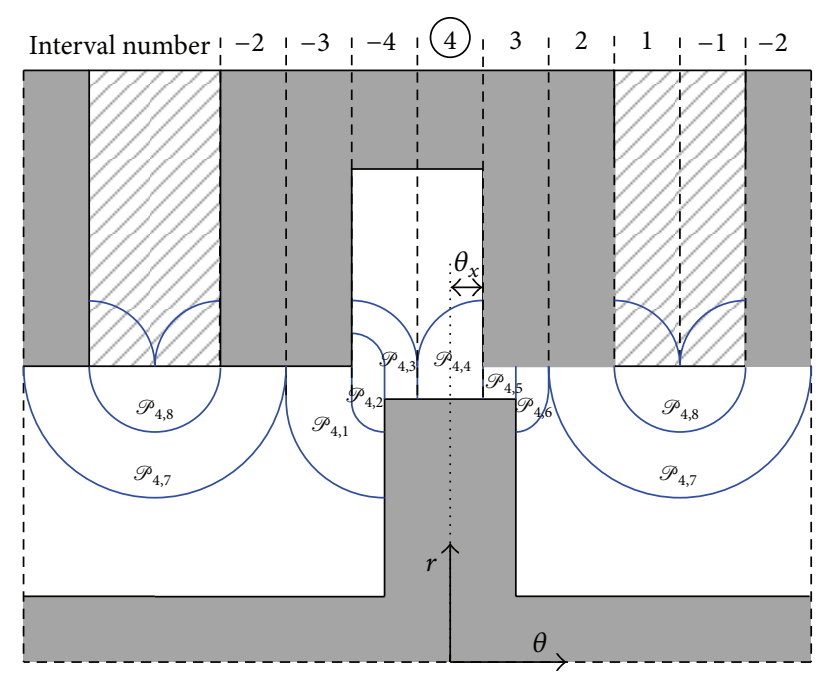

(a)

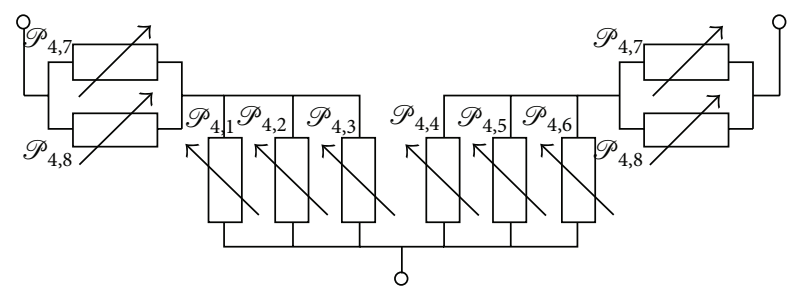

(b)

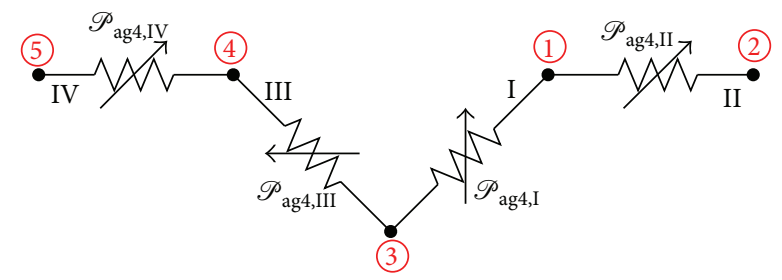

(c)

FIgure 13: Airgap MEC module 4: (a) flux tubes in the airgap while a rotor tooth travels in interval 4; (b) detailed magnetic equivalent circuit; (c) topology of airgap MEC module 4.

TABLE 4: Magnetic properties.

\begin{tabular}{lccc}
\hline Description & Symbol & Value & Unit \\
\hline Steel lamination type & M400-50A & - & - \\
PM remanent flux density & $B_{r}$ & 1.2 & $\mathrm{~T}$ \\
PM relative permeability & $\mu_{r}$ & 1.05 & - \\
\hline
\end{tabular}

they are competitive candidates for in-wheel traction systems. However, the analysis of FSMs presents difficulty due to their complex structure and heavy magnetic saturation.

The magnetic equivalent circuit (MEC) method is recommended as it provides a good compromise between computational time and accuracy. However, constructing a global MEC for FSMs that varies in synchronism with the rotor position is an elaborate work due to their double-salient structure and low periodicity.

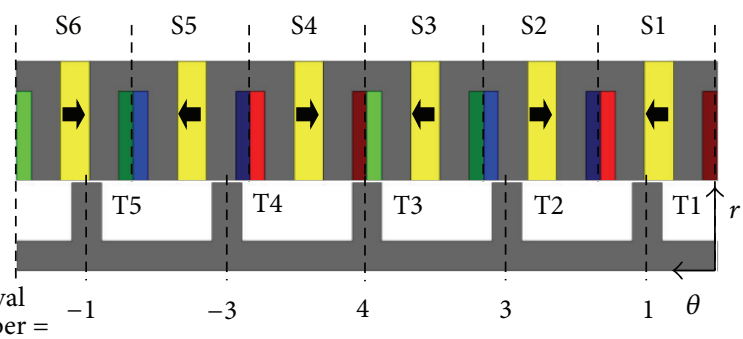

(a)

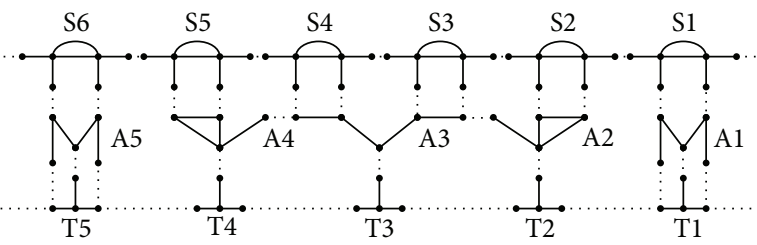

(b)

FIgURE 14: Global MEC of half of 12/10 FSPMM at a certain rotor position: (a) cross-section in polar coordinate; (b) network topology.

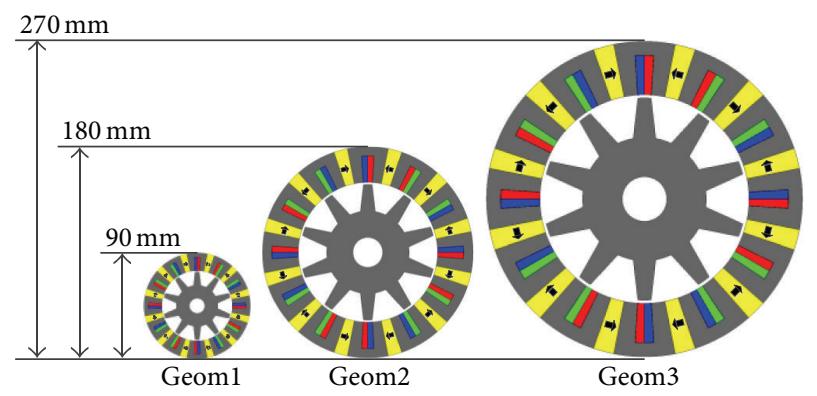

FIGURE 15: Cross-sections of three FSPMM models in various motor sizes.

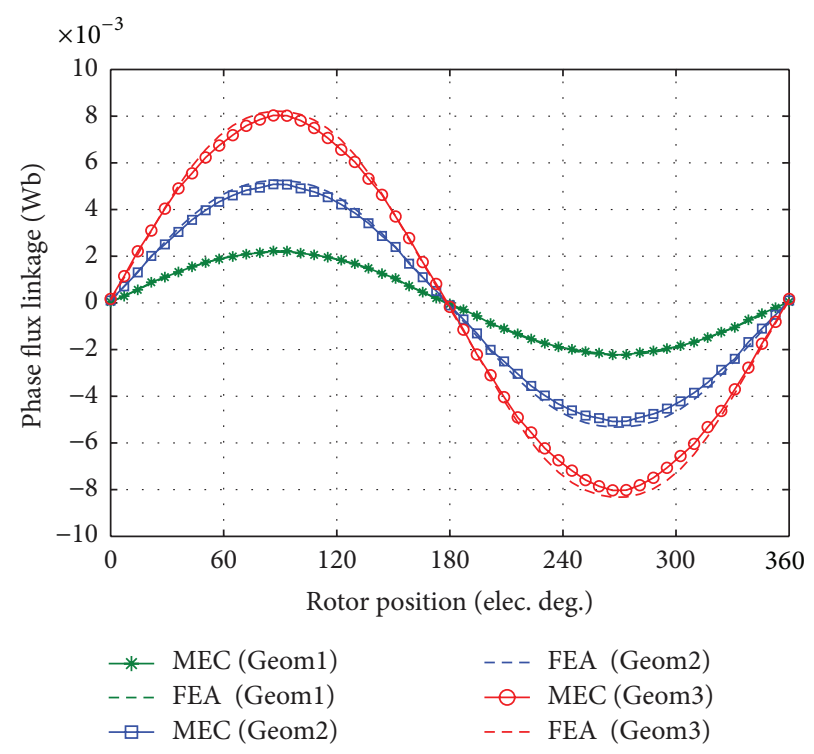

FIgURE 16: Open-circuit phase flux linkages of 12/10 flux-switching permanent magnet motor (FSPMM) in various sizes, obtained using magnetic equivalent circuits (MEC) and finite element analysis (FEA). 


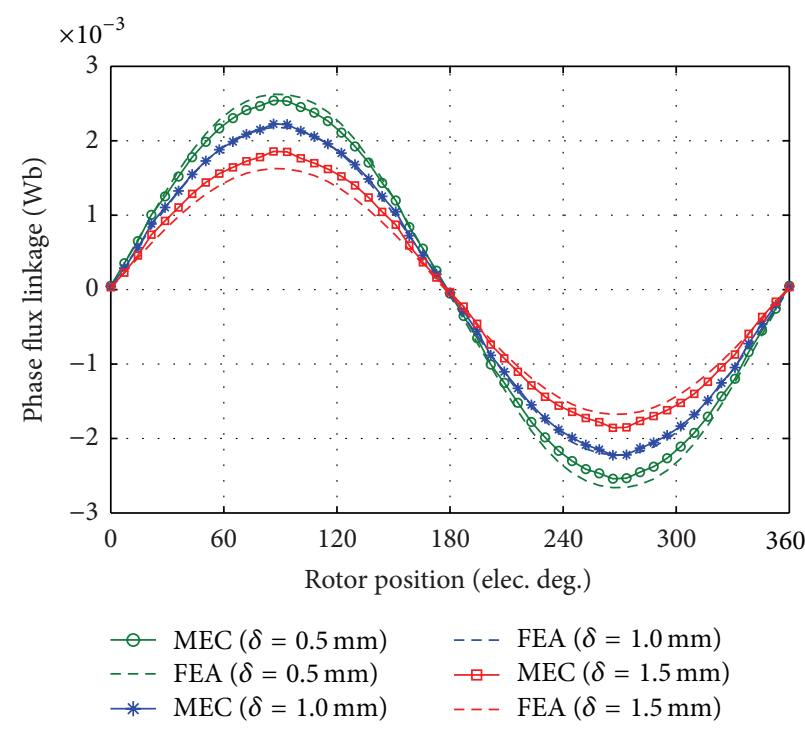

(a)

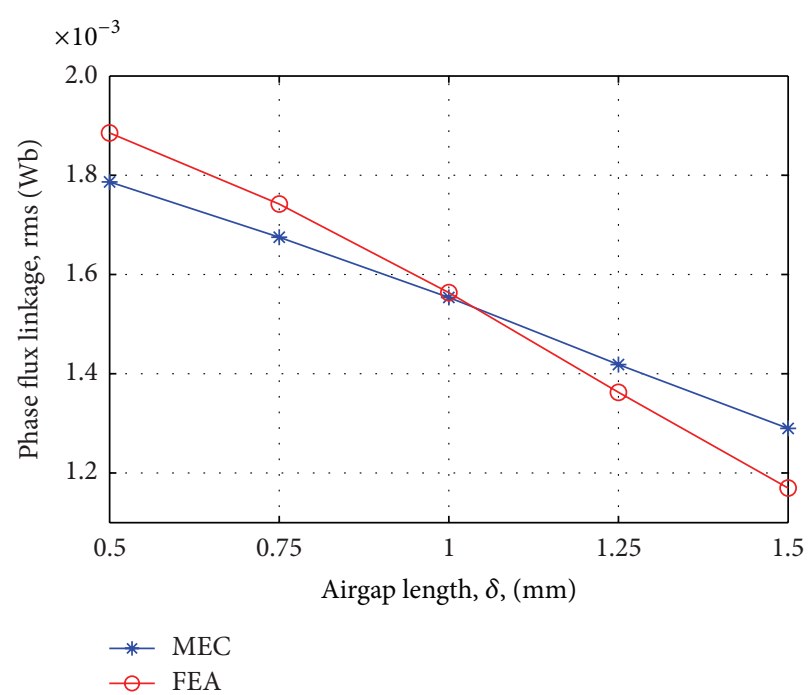

(b)

FIGURE 17: Open-circuit phase flux linkages of 12/10 flux-switching permanent magnet motor (FSPMM) with the airgap length varying from $0.5 \mathrm{~mm}$ to $1.5 \mathrm{~mm}$, obtained using magnetic equivalent circuits (MEC) and finite element analysis (FEA): (a) waveforms of the phase flux linkage; (b) root-mean-square ( $\mathrm{rms}$ ) values of the phase flux linkage.

TABLE 5: Geometric parameters of three flux-switching PM motors.

\begin{tabular}{lccccc}
\hline Description & Symbol & Geoml & Geom2 & Geom3 & Unit \\
\hline Stack length & $L$ & 120 & 120 & 120 & $\mathrm{~mm}$ \\
Stator outer diameter & $D_{\mathrm{SO}}$ & 90 & 180 & 270 & $\mathrm{~mm}$ \\
Stator back iron height & $h_{\mathrm{si}}$ & 3.6 & 7.2 & 10.8 & $\mathrm{~mm}$ \\
Stator slot depth & $h_{\mathrm{s}}$ & 14 & 28 & 42 & $\mathrm{~mm}$ \\
Rotor outer diameter & $D_{\mathrm{RO}}$ & 54 & 108 & 162 & $\mathrm{~mm}$ \\
Rotor back iron height & $h_{\mathrm{ri}}$ & 10 & 20 & 30 & $\mathrm{~mm}$ \\
Rotor tooth height & $h_{\mathrm{rt}}$ & 10 & 20 & 30 & $\mathrm{~mm}$ \\
Airgap length & $\delta$ & 1 & 1 & 1 & $\mathrm{~mm}$ \\
\hline
\end{tabular}

This paper presents a methodology to rapidly construct, adapt, and solve the global MEC of 12-stator-slot 10-rotortooth (12/10) FSMs. With this methodology, MEC models of different parts of FSM are defined, namely, stator MEC module, rotor MEC module, and airgap MEC module, in which the airgap MEC models are adaptive corresponding to the rotor position. Using the incidence matrix method, the global MEC is assembled with the MEC modules and iteratively solved to take into account the magnetic saturation.

Using this methodology, the variable global MEC of 12/10 FSM is constructed and used to investigate the correlations between certain design parameters and the open-circuit phase flux linakge. The results of the MEC model show a good agreement with the corresponding FEA results; thus, the accuracy of this methodology is validated. Therefore, this model is proved to be able to assist designers with the preliminary design of flux-switching motors for different in-wheel traction systems.

\section{Conflict of Interests}

The authors declare that there is no conflict of interests regarding the publication of this paper.

\section{References}

[1] E. A. Lomonova, E. Kazmin, Y. Tang, and J. J. H. Paulides, "Inwheel PM motor: compromise between high power density and extended speed capability," COMPEL, vol. 30, no. 1, pp. 98-116, 2011.

[2] Z. Q. Zhu and D. Howe, "Electrical machines and drives for electric, hybrid, and fuel cell vehicles," Proceedings of the IEEE, vol. 95, no. 4, pp. 746-765, 2007.

[3] R. Vos, I. J. M. Besselink, and H. Nijmeijer, "Influence of inwheel motors on the ride comfort of electric vehicles," in Proceeding of the 10th International Symposium on Advanced Vehicle Control (AVEC '10), pp. 835-840, Loughborough, UK, August 2010.

[4] E. V. Kazmin, E. A. Lomonova, and J. J. H. Paulides, "Brushless traction PM machines using commercial drive technologypart I: design methodology and motor design," in Proceedings of the International Conference on Electrical Machines and Systems (ICEMS '08), pp. 3801-3809, Wuhan, China, October 2008.

[5] S. E. Rauch and L. J. Johnson, "Design principles of fluxswitching alternators," AIEE Transactions, vol. 74, no. 3, pp. 1261-1268, 1955.

[6] Y. Tang, J. J. H. Paulides, T. E. Motoasca, and E. A. Lomonova, "Flux-switching motor with dc excitation," IEEE Transactions on Magnetics, vol. 48, no. 11, pp. 3583-3586, 2012.

[7] Y. Tang, T. E. Motoasca, J. J. H. Paulides, and E. A. Lomonova, "Comparison of flux-switching motors and permanent magnet synchronous machines in an in-wheel traction application," COMPEL, vol. 32, no. 1, pp. 153-165, 2013. 
[8] V. A. Kuznetsov and P. Brochet, "Numerical modelling of electromagnetic process in electromechanical systems," COMPEL, vol. 22, no. 4, pp. 1142-1154, 2003.

[9] W. L. Soong, D. A. Staton, and T. J. Miller, "Validation of lumped-circuit and finite-element modeling of axially-laminated brushless machines," in Proceedings of the 6th International Conference Electrical Machines and Drives, pp. 85-90, 1993.

[10] B. L. J. Gysen, E. Ilhan, K. J. Meessen, J. J. H. Paulides, and E. A. Lomonova, "Modeling of flux switching permanent magnet machines with fourier analysis," IEEE Transactions on Magnetics, vol. 46, no. 6, pp. 1499-1502, 2010.

[11] E. Ilhan, B. L. J. Gysen, J. J. H. Paulides, and E. A. Lomonova, "Analytical hybrid model for flux switching permanent magnet machines," IEEE Transactions on Magnetics, vol. 46, no. 6, pp. 1762-1765, 2010.

[12] E. Ilhan, J. J. H. Paulides, and E. Lomonova, "Fast torque estimation of in-wheel parallel flux switching machines for hybrid trucks," COMPEL, vol. 31, no. 1, pp. 40-53, 2012.

[13] E. Ilhan, M. Kremers, T. E. Motoasca, J. J. H. Paulides, and E. A. Lomonova, "Spatial discretization methods for airgap permeance calculations in double salient traction motors," IEEE Transactions on Industry Applications, vol. 48, no. 6, pp. 21652172, 2012.

[14] E. C. Lovelace, T. M. Jahns, and J. H. Lang, "A saturating lumped-parameter model for an interior PM synchronous machine," IEEE Transactions on Industry Applications, vol. 38, no. 3, pp. 645-650, 2002.

[15] M. Cheng, K. T. Chau, and C. C. Chan, "Nonlinear varyingnetwork magnetic circuit analysis for doubly salient permanent-magnet motors," IEEE Transactions on Magnetics, vol. 36, no. 1, pp. 339-348, 2000.

[16] T. Raminosoa, J. A. Farooq, A. Djerdir, and A. Miraoui, "Reluctance network modelling of surface permanent magnet motor considering iron nonlinearities," Energy Conversion and Management, vol. 50, no. 5, pp. 1356-1361, 2009.

[17] Z. Q. Zhu, Y. Pang, D. Howe, S. Iwasaki, R. Deodhar, and A. Pride, "Analysis of electromagnetic performance of fluxswitching permanent-magnet machines by nonlinear adaptive lumped parameter magnetic circuit model," IEEE Transactions on Magnetics, vol. 41, no. 11, pp. 4277-4287, 2005.

[18] A. Chen, R. Nilssen, and A. Nysveen, "Analytical design of a high-torque flux-switching permanent magnet machine by a simplified lumped parameter magnetic circuit model," in Proceedings of the 19th International Conference on Electrical Machines (ICEM '10), pp. 1-6, Rome, Italy, September 2010.

[19] J. L. G. Janssen, J. J. H. Paulides, E. A. Lomonova, and A. J. A. Vandenput, "Analysis of a variable reluctance permanent magnet actuator," in Proceedings of the IEEE Industry Applications Conference 42nd Annual Meeting (IAS '07), pp. 502-509, New Orleans, La, USA, September 2007.

[20] J. L. G. Janssen, J. J. H. Paulides, E. A. Lomonova, and A. J. A. Vandenput, "Cogging force reduction in tubular permanent magnet actuators," in Proceedings of the IEEE International Electric Machines and Drives Conference (IEMDC '07), pp. 266271, Antalya, Turkey, May 2007.

[21] A. V. Lebedev, E. A. Lomonova, P. G. van Leuven, J. Steinberg, and D. A. H. Laro, "Analysis and initial synthesis of a novel linear actuator with active magnetic suspension," in Conference Record of the IEEE Industry Applications Conference, 39th IAS Annual Meeting, pp. 2111-2118, October 2004.

[22] V. Ostovic, Dynamics of Saturated Electric Machines, Springer, Berlin, Germany, 1989.
[23] J. Makarovic, Lightweight positioning: design and optimization of an actuator with two-controlled degrees of freedom [Ph.D. thesis], Eindhoven University of Technology, Eindhoven, The Netherlands, 2006.

[24] L. O. Chua and P. M. Lin, Computer-Aided Analysis of Electronic Circuits-Algorithms and Computational Techniques, Prentice Hall, Englewood Cliffs, NJ, USA, 1975. 

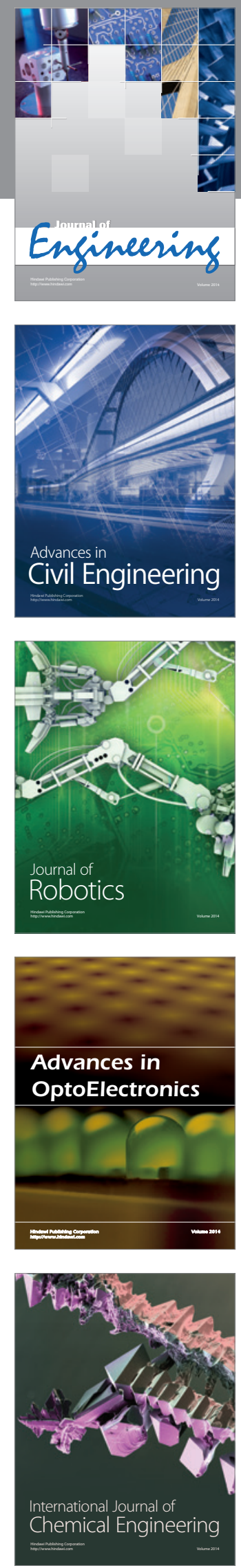

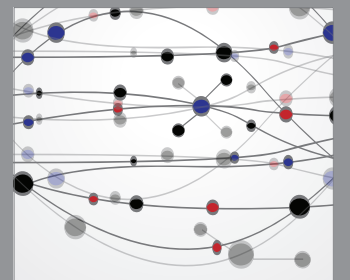

The Scientific World Journal
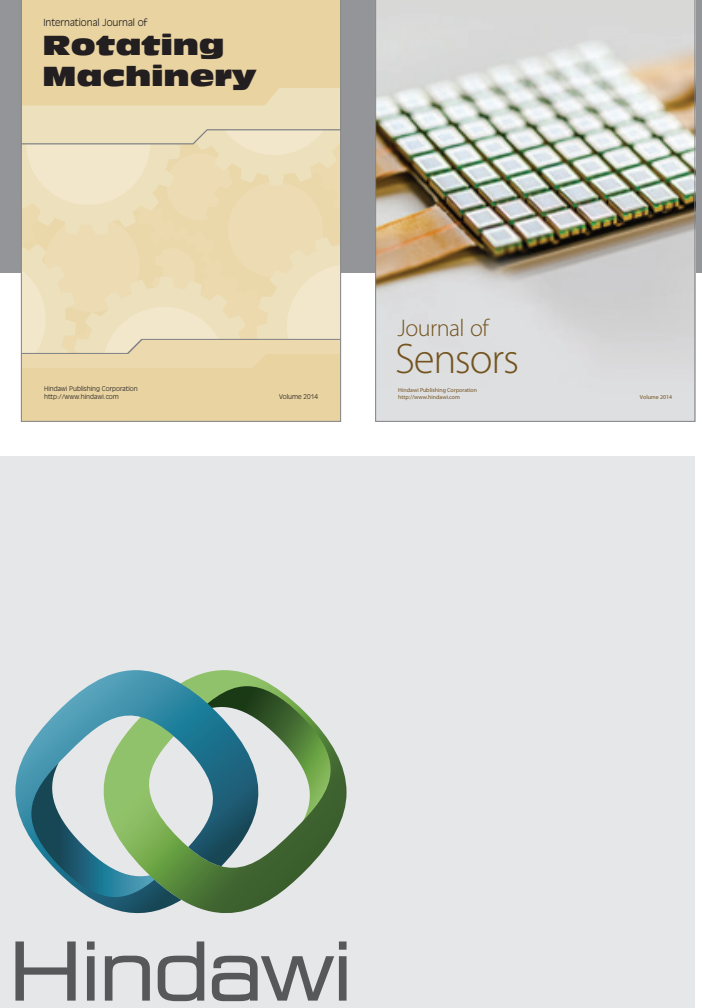

Submit your manuscripts at http://www.hindawi.com
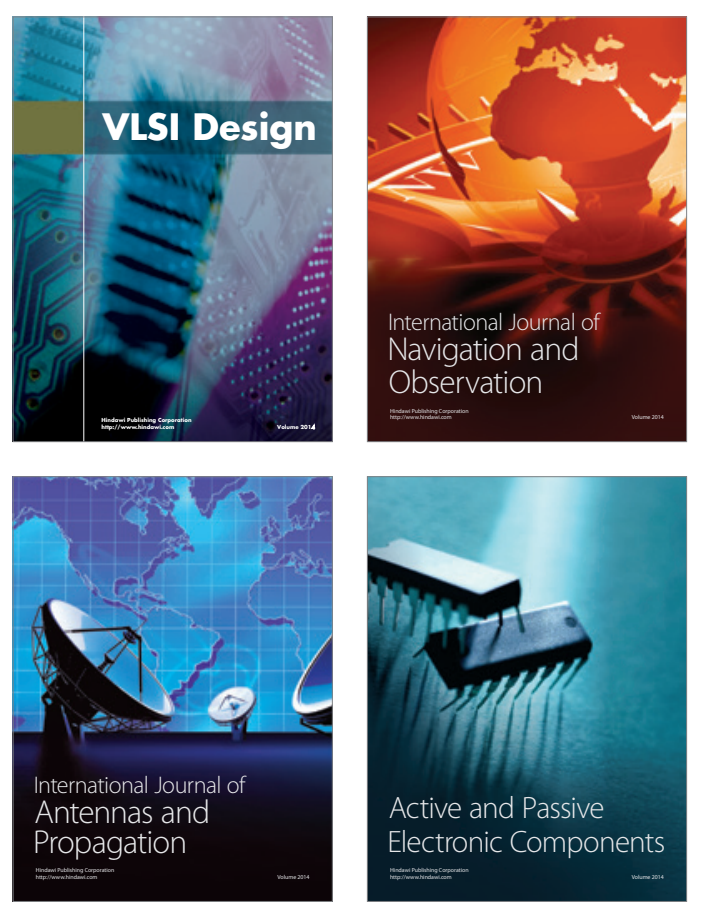
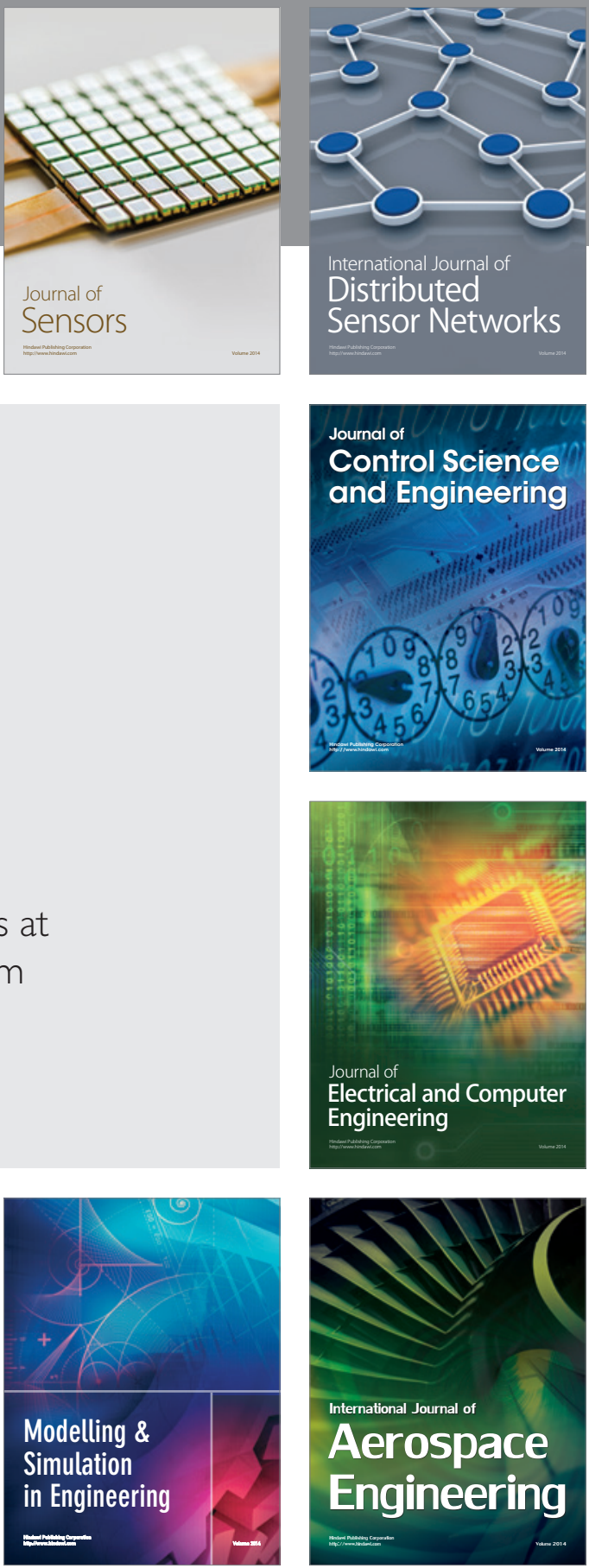

Journal of

Control Science

and Engineering
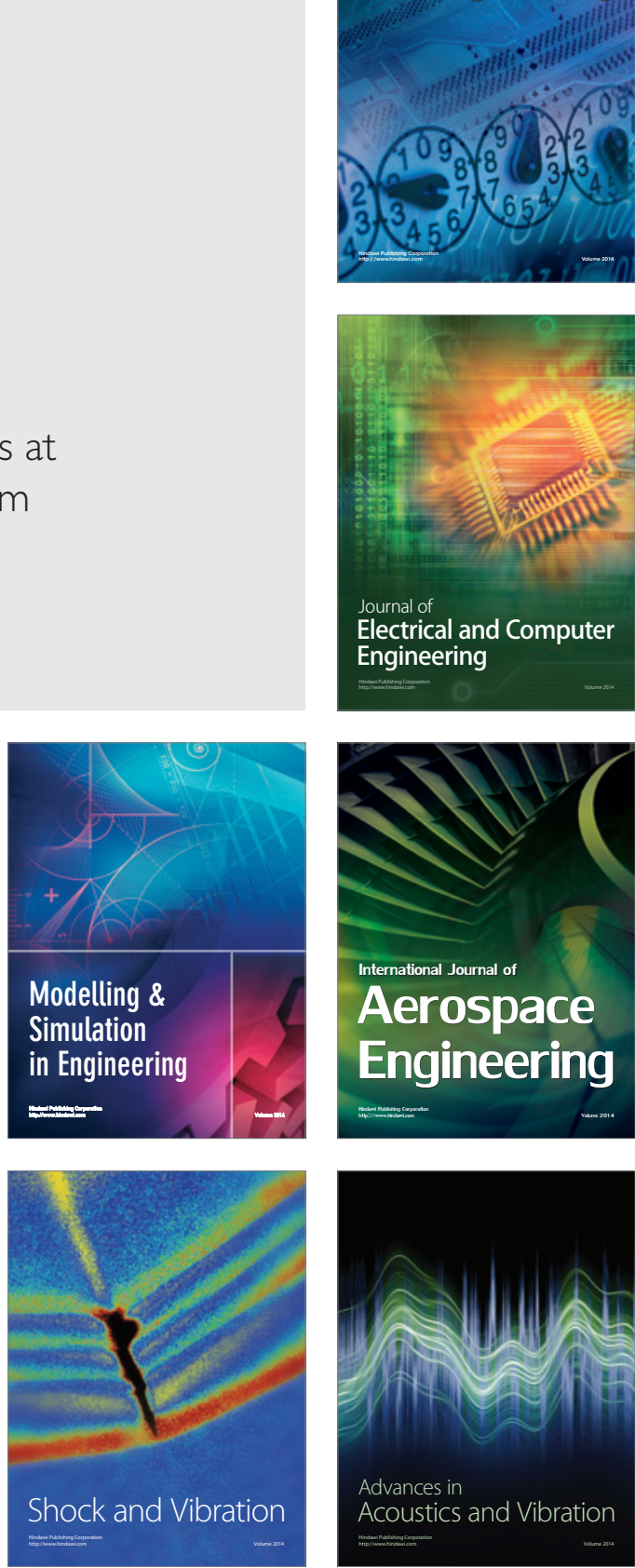